Wulp, I. van der, Poot, E.P., Nanayakkara, P.W.B., Loer, S.A., Wagner, C. Handover structure apel quality in the acute medical assessment unit: a prospective observational study. Journal of

\begin{tabular}{|l|l|}
$\begin{array}{l}\text { Postprint } \\
\text { Version }\end{array}$ & 1.0 \\
\hline Journal website & https://insights.ovid.com/pubmed?pmid=29112022 \\
\hline Pubmed link & $\underline{\text { https://www.ncbi.nlm.nih.gov/pubmed/29112022 }}$ \\
\hline DOI & $10.1097 /$ PTS.0000000000000221 \\
\hline
\end{tabular}

This is a NIVEL certified Post Print, more info at http://www.nivel.eu

\title{
Handover Structure and Quality in the Acute Medical Assessment Unit: A Prospective Observational Study
}

\author{
InEKe VAN DER WulP, PhD, ${ }^{*}$ Else P. POOT, MScN, $\uparrow$ PRABATH W.B. NANAYAKKaRA, \\ PHD, $¥$ STEPHAN A. LOER, PHD, $\S$ AND CORDULA WAGNER, PHD*\|
}

From the *Department of Social Medicine, VU University Medical Center/ EMGO+ Institute, Amsterdam, The Netherlands;

†Working Party on Infection Prevention, Leiden University Medical Center, Leiden, The Netherlands;

$¥$ Section of Acute Medicine, Department of Internal Medicine, VU University Medical Center, Amsterdam, The Netherlands;

$\S$ Department of Anesthesiology, VU University Medical Center, Amsterdam, The

Netherlands; and

||The Netherlands Institute of Health Services Research, NIVEL, Utrecht, the Netherlands.

Objectives: Inadequate patient handovers are associated with the occurrence of medical errors. The objective of the present study was to explore the structure and quality of handovers in the acute medical assessment unit. Methods: A prospective observational study was conducted in an academic hospital in the Netherlands. Handover structure was observed by ordering handover information according to the elements of the Situation, Background, Assessment, Recommendation, and Read back (SBAR-R) handover tool. Handover quality was measured by means of a questionnaire, i.e., the rating tool for handover quality, and by assessing situation awareness of the degree to which professionals after a handover agreed on the complexity of the patient's care needs.

Results: A total of 71 handovers were observed. In most handovers,

different elements of the SBAR-R were used frequently (median, 7.5 elements; range, 2.0-15.0). On the quality of handovers, 109 respondents $(44.1 \%)$ completed the questionnaire. On a 0-to-100 scale, median scores on information transfer were 67.9 (interquartile range [IQR],17.9), 75.0 (IQR, 25.0) on shared understanding, and 75.0 (IQR, 16.7) on working atmosphere. Agreement in situation awareness was $70.0 \%$.

Conclusions: Handovers in the acute medical assessment unit were poorly structured; however, the perceived quality of handovers was substantial. Implementing the SBAR-R may be an effective strategy to improve handover 
Wulp, I. van der, Poot, E.P., Nanayakkara, P.W.B., Loer, S.A., Wagner, C. Handover structure apel quality in the acute medical assessment unit: a prospective observational study. Journal of Patient Safety: 2019, 3, p. 224-229

practice and situation awareness, although further study to its applicability in acute medical assessment units is necessary.

In recent years, acute medical assessment units (AMAUs) have been introduced in hospitals, reducing emergency department length of stay, hospital length of stay, and mortalty. ${ }^{1}$ Acute medical assessment units admit patients from the emergency department with acute illnesses up to 72 hours for further observation and treatment. ${ }^{2}$ However, by implementing these units, an additional care transition has been introduced in the acute care chain, increasing the risk of medical error, e.g., owing to inadequate handover. In inadequate handovers, clinical relevant information is omitted, incomplete or handed over fragmentarily, e.g., owing to inadequate preparation, the absence of a designated handover area or a lack of time. ${ }^{3,4}$ They are a frequent cause of medical error. ${ }^{3,5,6}$ Moreover, inadequate handovers may affect situation awareness of the professional receiving information. Situation awareness is a process that comprises collecting information about the patient's status, understanding the patient's situation including relevant events, and as a result, the ability to estimate future events. ${ }^{7}$ It is essential in decision making. Adequate training and the use of handover tools improve the structure of handovers. ${ }^{8}$ Of these tools, the Situation, Background, Assessment, Recommendation, and Read back (SBAR-R) handover tool is most frequently used. ${ }^{9,10}$ Studies measuring the effects of implementing the SBAR-R on patient care showed encouraging results. Two studies reported an increase in the precision of patient information that was handed over.11,12 In addition, Marshall et al ${ }^{13,14}$ and McCrory et a ${ }^{15}$ reported improvements in the content and clarity of the information handed over. Furthermore, 2 studies reported a decrease in the number of adverse events and order entry errors. ${ }^{16,17}$ In 3 studies, teamwork and user satisfaction with the SBAR-R were evaluated. Moseley et $\mathrm{al}^{12}$ reported greater resident satisfaction. Beckett and Kipnis ${ }^{18}$ and Carroll ${ }^{19}$ reported, among other things, that the communication about errors within the team improved. Finally, 2 studies reported an increase in the time professionals spent on verbal communication. ${ }^{15,20}$ The before mentioned studies were mainly focused on settings that differ from the AMAU. Before evaluating its effects, knowledge about current handover practices in the AMAU, when no structured handover tool was implemented, is necessary to determine the need for such a tool. Therefore, the objective of this study was to explore the structure and quality of handovers in the AMAU.

\section{METHODS}

\section{Design}

A prospective observational study was conducted.

\section{Study Setting and Population}

The study was conducted in the AMAU of an academic medical center in the Netherlands. The AMAU was operative since December 2012, had 24 beds available, and was open day and night. The AMAU admitted patients older than 16 years of age who were admitted for diagnosis, treatment, or further observation. Patients were admitted from the emergency department or the outpatient department. These patients were treated by a variety of specialties including internal medicine, surgery, orthopedics, neurology, urology, gastroenterology, and pulmonology. 
Wulp, I. van der, Poot, E.P., Nanayakkara, P.W.B., Loer, S.A., Wagner, C. Handover structure apel quality in the acute medical assessment unit: a prospective observational study. Journal of Patient Safety: 2019, 3, p. 224-229

Patients' maximum length of stay at the AMAU was 48 hours after which they were discharged from the hospital or transferred to a nursing unit within the hospital. No handover tools were formerly implemented on the AMAU; however, a Dutch version of the SBAR-R was already available on the hospital's intranet. The tool could be accessed by all employees of the hospital. The AMAU staff were not trained to use the SBAR-R and not made aware of its presence on the intranet. Before the study, 2 researchers (E.P. and I.v.d.W.] observed practices in the AMAU. During these days, it was noticed that most patients were admitted for the surgery and internal medicine specialties. Therefore, it was decided to focus the present study on these handovers. Consequently, all handovers of patients transferred from the AMAU to a nursing ward with a surgeon or internal medicine specialist as the treating physician were included in the study.

\section{Data Collection}

The structure of patient handovers in the AMAU was studied by observing 2 types of handovers, i.e., nursing transfer handovers and medical shift handovers. Nursing transfer handovers were conducted in the AMAU and comprised handovers of individual patients who transferred from the AMAU to another ward in the same hospital. Medical shift handovers comprised handover sessions in which several patients were handed over from the doctor whose shift ended to the doctor on duty next. These sessions were conducted in a designated area outside the AMAU. Observations were registered on a list designed for the present study. The list registered, date, type of handover (nursing transfer or medical shift), specialty (internal medicine or surgery), number of interruptions (e.g., a colleague asking a question during handover), number of disruptions (e.g., another conversation in the same room), and the number of times the elements of the SBAR-R occurred in handovers. Observations were conducted daily between 8 A.M. and 6 P.M. from April 2 to May 24, 2013 by one researcher (E.P.). To measure the quality of handovers with regard to agreement in situation awareness, after each observation, the professionals present at the handover were asked to independently rate the complexity of the patient's care needs. Ratings were made on a 5-point Likert scale ranging from very low complexity to very high complexity. Furthermore, they were asked to rate the quality of the handover by responding to the following: Overall, the quality of this handover was very high. ${ }^{21}$ In addition, all (resident) doctors and nurses who attended the AMAU approximately once a week were sent a questionnaire by email. The questionnaire comprised the rating tool for handoff quality ${ }^{21}$ and was used to measure the perceived quality of handovers in the AMAU in general. The rating tool for handoff quality comprised 19 items measuring 3 dimensions, i.e., information transfer, shared understanding, and working atmosphere. Information transfer comprises items that deal with the way information is handed over and the completeness and relevancy of this information. ${ }^{21}$ Items belonging to shared understanding ask to what degree questions and potential risks have been clarified and discussed. Finally, working atmosphere comprises items that handle about tensions or other aspects that may limit the correct transfer of information. Items on the rating tool for handoff quality were scored on a 4-point Likert scale (agree, partially agree, partially disagree, and disagree). The dimensions of the tool were found to be associated with the overall perceived quality of handovers (predictive validity). ${ }^{21}$ 
Wulp, I. van der, Poot, E.P., Nanayakkara, P.W.B., Loer, S.A., Wagner, C. Handover structure apel quality in the acute medical assessment unit: a prospective observational study. Journal of Patient Safety: 2019, 3, p. 224-229

\section{Use and Implementation of the SBAR-R in Handover Practice}

The SBAR-R is an extension of the SBAR handover tool. Situation describes information about what is going on with the patient, e.g., the patient currently experiences a headache while being admitted for irregular blood sugar levels (Leonard et al 2004). ${ }^{22}$ Information about the patient such as sex, age, or blood pressure was handed over in the background part of a handover. Furthermore, assessment handles the problem that most likely causes the situation, e.g., an adverse effect to new glucose lowering drugs. In "Recommendation", the person handing over addresses what actions need to be taken, e.g., monitoring of the patient's headache, provision of a pain killer, and calling the doctor on duty when the patient's pain score remains 4 or higher over the next 8 hours. Finally, to ensure the information has been handed over correctly, the receiver repeats which actions will be taken ("Read back"). In implementing the SBAR-R, a number of effective strategies have been identified including support from senior (medical) staff, educational team sessions, laminated posters or cards, designated SBAR-R handover forms, and a helpline. ${ }^{16}$

\section{Translation and Cross-cultural Validation of the Rating Tool for Handoff Quality}

The rating tool for handoff quality was translated from English to Dutch by one of the researchers (E.P.). For back translation, it was sent to a translator whose first language was British English. The resulting translation was compared to the original questionnaire, and disagreements were discussed. To determine if the translation had the same 3-factor structure as previously reported, i.e., information transfer, shared understanding, and working atmosphere, ${ }^{21}$ a confirmatory factor analysis was conducted. Model fit was evaluated by means of the root mean square error of approximation. In addition, the factor loadings of the confirmatory factor analysis were compared to those reported previously. ${ }^{21}$ Internal consistency of the translated questionnaire was determined by means of Cronbach alpha correlations within the 3 factors. Analyses were conducted in R for Windows (version 3.0.1). ${ }^{23}$

\section{Data Analyses}

Handover characteristics were analyzed by means of descriptive statistics. The structure of handovers was reported by calculating the frequency with which each SBAR-R element, i.e., situation, background, assessment, recommendation, and read back, was present in handovers. Moreover, from the observations, the number of times each SBAR-R element occurred in a handover was summed. The resulting number was indicative of the structure of the handovers, i.e., the higher the score, the more frequently the information had to be ordered in a different SBAR-R element and the poorer the structure of the handover.

Data on the quality of handover practice in the AMAU in general were analyzed by summing the scores on the items of the rating tool for handoff quality belonging to the same subscale. For the ease of interpretation, the resulting scores were converted in 0 to 100 scores. Before calculating the scores, negatively worded items ${ }^{3,10,14,15}$ were reverse coded. Table 1 presents the items of the rating tool for handoff quality. In addition, the percentage agreement in situation awareness between the professionals present at the handover was calculated. Furthermore, it was tested to 
Wulp, I. van der, Poot, E.P., Nanayakkara, P.W.B., Loer, S.A., Wagner, C. Handover structure apel quality in the acute medical assessment unit: a prospective observational study. Journal of Patient Safety: 2019, 3, p. 224-229

what degree an association existed between agreement in situation awareness and the structure and quality of the handover (both measured directly after the handover). Therefore, univariate logistic regression analyses were conducted. In these analyses, agreement in situation awareness (agree or disagree) was the dependent variable, and the structure or quality rating of the handover was an independent variable. Analyses were conducted in $\mathrm{R}$ for Windows (version 3.0.1). ${ }^{23}$

\section{Institutional Review Board Approval}

The study was conducted with the intention of regular quality improvement work by the AMAU; no patient data or involvement was required. The study protocol was therefore exempted from review by the Medical Ethical Committee, which is in agreement with he Dutch law. Before observing handovers, professionals were informed about the study and asked permission for observation.

\section{[TABLE 1]}

\section{RESULTS}

\section{Handover Structure}

A total of 74 handovers of patients took place in the AMAU during the study period of which 71 were observed. Three handovers could not be observed because the researcher was not notified in time about the time or location of the handover. Compared to nursing transfer handovers, in medical shift handovers, information was more likely structured according to the SBAR-R, i.e., median number of elements, 4.0 (range, 1.0-12.0) versus 7.5 (2.0-15.0), respectively. Table 2 shows for each SBAR-R element the number of handovers in which the element was present. In nursing transfer handovers, information related to situation, background, and recommendation was most frequently handed over. In medical shift handovers, information related to background and assessment was most frequently mentioned. When comparing both types of handovers, information related to situation was significantly $(P<0.01)$ more often handed over in nursing transfer handovers, whereas in medical shift handovers, information related to assessment was more often handed over $(P=0.04)$. Sixteen $(40.0 \%)$ of the nursing transfer handovers contained all elements of SBAR of which in $4(10.0 \%)$ also read back was observed. In medical shift handovers, 9 (26.5\%) comprised all SBAR elements; read back was not observed in medical shift handovers. These differences between nursing transfer and medical shift handovers were not statistically significant, i.e., $P=0.34$ and $P=$ 0.20 , respectively.

\section{[TABLE2]}

\section{Cross-cultural Validation Check of Rating Tool for Handoff Quality}

A total of 247 nurses and physicians were sent a questionnaire of which 109 (44.1\%) responded. Their characteristics are described in Table 3. Of these, 24 respondents only completed the questions measuring demographic characteristics. These re spondents were removed from the analyses. Of the remaining data, $6.6 \%$ of the information was missing in which a monotone pattern was observed. For example, 
Wulp, I. van der, Poot, E.P., Nanayakkara, P.W.B., Loer, S.A., Wagner, C. Handover structure apel quality in the acute medical assessment unit: a prospective observational study. Journal of Patient Safety: 2019, 3, p. 224-229

16 respondents (18.8\%) had missing data on 4 items of which 2 (i.e., items 9 and 10) were related to the dimension "working atmosphere". To increase the power of the confirmatory factor analysis, missing data were imputed by means of multiple regression analyses in a single imputation procedure, taking into account the monotone missing data pattern. In the resulting data set, no significant differences $(P$ $>0.05)$ were found between the distributions of the observed and imputed data. In confirmatory factor analysis, the factor structure reported by Manser et $\mathrm{al}^{21}$ was tested on the data of the present study. The root mean square error of approximation was 0.06 , indicating good model fit. ${ }^{24}$ Table 4 presents the original factor loadings of the rating tool for handoff quality and the factor loadings of the present study. When these were compared, smaller loadings were found on items 2 and 3 (information transfer), item 12 (shared understanding), and items 9 and 10 (working atmosphere). Other items had comparable or higher loadings. In addition, the internal consistency of the 3 factors was moderate to good for factor 1: information transfer (Cronbach $\alpha, 0.74 ; 95 \%$ confidence interval [CI], 0.61-0.82) and factor 2: shared understanding (Cronbach $\alpha, 0.63$; 95\% CI, 0.50$0.74)$, whereas it was fair for factor 3 :

working atmosphere (Cronbach $\alpha, 0.40 ; 95 \% \mathrm{CI}, 0.14-0.59$ ). As the factor structure holds and internal consistency was acceptable, the scores of the rating tool for handoff quality were calculated for the 3 dimensions.

\section{[TABLE 4]}

\section{Handover Quality}

On the rating tool for handoff quality, the quality of the information transferred as perceived by professionals was substantial, i.e., median overall score, 67.9 (interquartile range [IQR), 17.9] on a 100-point scale. On the subscales shared understanding (median, 75.0; IQR, 25.0) and working atmosphere (median, 75.0; IQR, 16.7), scores were comparably high. Table 1 presents the responses on the individual items of the rating tool for handoff quality. Most $(55.3 \%)$ of the respondents (partly) agreed on the proposition that in general, the quality of handovers in the AMAU was very high. However, respondents experienced time pressures during handovers, as they indicated that the person handing over $(85.3 \%)$ or the person taking over responsibility for a patient $(64.7 \%)$ were under time pressure. Relatedly, most (54.2\%) indicated not enough time was calculated for handovers.

\section{[TABLE 3]}

\section{Situation Awareness}

In 30 handovers, the nurses present at the handover independently estimated the complexity of the patient's needs in which they agreed in 21 handovers $(70.0 \%)$. Compared to the nurse handing over patient care, the nurse taking over patient care underestimated the patient's need in 7 handovers $(23.3 \%)$. In logistic regression analysis, the association between agreement in situation awareness and the perceived quality and structure of the handover (measured directly after handover) were determined. It was found that professionals taking over care and (partly) agreeing with the proposition that handover quality was high were more likely to agree in 
Wulp, I. van der, Poot, E.P., Nanayakkara, P.W.B., Loer, S.A., Wagner, C. Handover structure apel quality in the acute medical assessment unit: a prospective observational study. Journal of Patient Safety: 2019, 3, p. 224-229

situation awareness compared to professionals who (partly) disagreed on the statement (odds ratio, 1.42; 95\% CI, 0.17-9.47; $P=0.72$ ). Furthermore, the more frequently one interchanged between the SBAR-R elements during a handover, the less likely professionals agreed on situation awareness (odds ratio, 0.76; 95\% CI, $0.54-0.99 ; P=0.06)$.

\section{DISCUSSION}

In this study, the structure and quality of handovers in an AMAU was explored. It was found that in medical shift handovers, compared to nursing transfer handovers, information was more likely structured according to the SBAR-R, implying that hand overs were better structured. Another difference between nursing transfer and medical shift handovers occurred in verifying information that was handed over. In medical shift handovers, no information was verified in any of the handovers, whereas in nursing transfer handovers, a few attempts were made. In studying the quality of handovers, it was found that doctors and nurses in the AMAU experienced the quality of the handovers in general as substantial. In nursing transfer handovers, this was also reflected in that nurses taking over patient care were fairly well aware of the complexity of the patient's need after handover.

The lack of structure in handovers as found in the present study potentially affected situation awareness and decision making. However, substantial agreement in situation awareness between nurses was found. Moreover, also other factors such as leadership, workload, and one's ability to process information influence situation awareness. ${ }^{7,25}$ Its exact influence therefore cannot be defined. Regarding the structure of handovers, the findings of the present study differ slightly from the findings of Ilan et al. ${ }^{26}$ In that study, physicians handing over patients interchanged between SBAR elements more frequently compared to the present study. Also in that study, the element recommendation was more often absent in handovers. In addition, in Poot et al, ${ }^{27}$ the number of handovers in which all SBAR elements were present differed from what was found in the present study, i.e., 6.7\% (medical) and 7.5\% (nursing) compared to $26.5 \%$ (medical) and $40 \%$ (nursing). Differences may be explained by the setting in which both studies were conducted, i.e., the intensive care unit and perinatal care unit.

Another explanation may be the fact that both studies observed a limited amount of handovers for which the generalizability of the findings reported may be limited. Furthermore, the limited amount of time available, as experienced by respondents in the present study, may also explain why in medical shift handovers information was not verified. Verifying information in handovers was introduced by Patterson et $\mathrm{al}^{28}$ as a strategy to ensure that information was accurately handed over. In an evaluation of the effects of this strategy, Barenfanger et $\mathrm{al}^{29}$ reported a $3.5 \%$ reduction in the error rate of communicating laboratory results. However, it was not present in most of the handovers, which is comparable to findings in other studies. ${ }^{29,30}$ Further study is necessary to explore the reasons for not verifying information. Additionally, it is important to decrease time pressures during handover. This may be accomplished by implementing a structured handover tool such as the SBAR-R. Although previous studies have shown that the time required to handover increases after implementing such a tool, ${ }^{15,20}$ it causes fewer task errors, ${ }^{32}$ which ultimately decreases time pressures. 
Wulp, I. van der, Poot, E.P., Nanayakkara, P.W.B., Loer, S.A., Wagner, C. Handover structure apel quality in the acute medical assessment unit: a prospective observational study. Journal of

\section{Implications for Practice}

In the present study, it was found that professionals' situation awareness was dependent of the structure of a handover. The SBAR-R may therefore be an effective strategy to improve the structure of handovers in the AMAU. However, it may be necessary to adjust the order in which the SBAR-R elements are handed over or, following McCrory et al, ${ }^{15}$ specify elements such as the airway, breathing, and circulation rule to the SBAR-R. Furthermore, the findings of the present study may be helpful in defining a strategy for implementing the SBAR-R in AMAUs. As the structure of handovers differed between nurses and physicians, different implementation strategies may be necessary.

\section{Limitations}

Several aspects, which potentially limit the interpretation of the reported findings, need to be taken into account. First, the structure of handovers was explored by ordering the information according to the SBAR-R handover tool. It may be that handovers showed better structure when other handover tools were used. ${ }^{26}$ Second, the data were collected in one hospital; and therefore, the generalizability of the study findings is limited. Third, the response to the questionnaire on the quality of handovers in the AMAU was limited. The experienced quality of handovers may therefore be overestimated. Fourth, for practical reasons the handover observations were conducted by one researcher. Despite the fact that at the start of the study, agreement between 2 researchers was sought on how to interpret the observation items, one observer may still have had influence on the reported findings. Fifth, before the study, the researchers were present during 3 days on the AMAU to study handover practices and make professionals aware of the study. Finally, the SBAR-R handover tool was online, available for all employees of the hospital. This, combined with the presence of an observer at the handovers, could have influenced the reported findings. Possibly, handovers were structured more properly in the present study compared to the situation in which no observer was present. On the other hand, the effects of these factors may be limited, as from previous studies, it is known that training sessions are necessary in adoption of the SBAR-R by professionals. ${ }^{19}$

\section{CONCLUSIONS}

A structure in handovers conducted in the AMAU was lacking in most handovers, although the perceived quality of handovers in general was substantial. In addition, the information handed over was rarely verified by the professional taking over the care

for a patient. The results also showed that the more structured a handover, the better the situation awareness of the professional taking over the care. To structure handovers and further increase the quality of handovers in the AMAU, implementation of the SBAR-R may be an effective strategy. This may improve situation awareness and decision making in the AMAU. Further study is necessary to explore the applicability of the SBAR-R format in AMAUs. 
Wulp, I. van der, Poot, E.P., Nanayakkara, P.W.B., Loer, S.A., Wagner, C. Handover structure apel quality in the acute medical assessment unit: a prospective observational study. Journal of

Patient Safety: 2019, 3, p. 224-229

\section{REFERENCES}

Scott I, Vaughan L, Bell D. Effectiveness of acute medical units in hospitals: a systematic review. Int J Qual Health Care. 2009; 21:397-407.

Bell $\mathrm{D}$, Skene $\mathrm{H}$, Jones $\mathrm{M}$, et al. A guide to the acute medical unit. Br J Hosp Med (Lond). 2008;69:M107-M109.

Raduma-Tomas MA, Flin R, Yule S, et al. Doctors' handovers in hospitals: a literature review. BMJ Qual Saf. 2011;20:128-133.

Raduma-Tomas MA, Flin R, Yule S, et al. The importance of preparation for doctors' handovers in an acute medical assessment unit: a hierarchical task analysis. BMJ Qual Saf. 2012;21:211-217.

Horwitz LI, Meredith T, Schuur JD, et al. Dropping the baton: a qualitative analysis of failures during the transition from emergency department to inpatient care. Ann Emerg Med. 2009;53:701-710.

Pham JC, Story JL, Hicks RW, et al. National study on the frequency, types, causes, and consequences of voluntarily reported emergency department medication errors. J Emerg Med. 2011;40:485-492.

Endsley MR. Toward a theory of situation awareness in dynamic systems. Human Factors. 1995;37:32-64.

Dawson S, King L, Grantham H. Review article: improving the hospital clinical handover between paramedics and emergency department staff in the deteriorating patient. Emerg Med Australas. 2013;25:393-405.

Riesenberg LA, Leitzsch J, Massucci JL, et al. Residents' and attending physicians' handoffs: a systematic review of the literature. Acad Med. 2009;84:1775-1787.

Riesenberg LA, Leitzsch J, Cunningham JM. Nursing handoffs: a systematic review of the literature. Am J Nurs. 2010;110:24-34.

Grover A, Duggan E. Chinese whispers in the post anaesthesia care unit (PACU). Ir Med J. 2013;106:241-243.

Moseley BD, Smith JH, Diaz-Medina GE, et al. Standardized sign-out improves completeness and perceived accuracy of inpatient neurology handoffs. Neurology. 2012;79:1060-1064.

Marshall S, Harrison J, Flanagan B. The teaching of a structured tool improves the clarity and content of interprofessional clinical communication. Qual Saf Health Care. 2009;18:137-140.

Marshall SD, Harrison JC, Flanagan B. Telephone referral education, and evidence of retention and transfer after six months. BMC Med Educ. 2012;12:38.

McCrory MC, Aboumatar H, Custer JW, et al. "ABC-SBAR" training improves simulated critical patient hand-off by pediatric interns. Pediatr Emerg Care. 2012;28:538-543.

Haig KM, Sutton S, Whittington J. SBAR: a shared mental model for improving communication between clinicians. Jt Comm J Qual Patient Saf. 2006;32:167-175.

Telem DA, Buch KE, Ellis S, et al. Integration of a formalized handoff system into the surgical curriculum: resident perspectives and early results. Arch Surg. 2011;146:89-93.

Beckett CD, Kipnis G. Collaborative communication: integrating SBAR to improve quality/patient safety outcomes. J Healthc Qual. 2009;31:19-28.

Carroll TL. SBAR and nurse-physician communication: pilot testing an educational intervention. Nurse Admin Q. 2006;30:295-299.

Cornell P, Gervis MT, Yates L, et al. Improving shift report focus and consistency with the situation, background, assessment, recommendation protocol. J Nurs Adm. 2013;43:422428.

Manser T, Foster S, Gisin S, et al. Assessing the quality of patient handoffs at care transitions. Qual Saf Health Care. 2010;19:e44.

Leonard M, Graham S, Bonacum D. The human factor: the critical importance of effective teamwork and communication in providing safe care. Qual Saf Health Care. 2004;13:i85i90.

R Foundation for Statistical Computing. $\mathrm{R}$ [computer program], a language and environment for statistical computing. Vienna, Austria: R Foundation for Statistical Computing; 2013. 
Wulp, I. van der, Poot, E.P., Nanayakkara, P.W.B., Loer, S.A., Wagner, C. Handover structure anel quality in the acute medical assessment unit: a prospective observational study. Journal of

Patient Safety: 2019, 3, p. 224-229

Schreiber JB, Stage FK, King J, et al. Reporting structural equation modeling and confirmatory factor analysis results: a review. The Journal of Educational Research. 2006;99:323-337.

Stubbings L, Chaboyer W, McMurray A. Nurses' use of situation awareness in decisionmaking: an integrative review. J Adv Nurs. 2012;68:1443-1453.

Ilan R, LeBaron CD, Christianson MK, et al. Handover patterns: an observational study of critical care physicians. BMC Health Serv Res. 2012;12:11.

Poot EP, de Bruijne MC, Wouters MG, et al. Exploring perinatal shift-to-shift handover communication and process: an observational study. J Eval Clin Pract. 2014;20:166-175.

Patterson ES, Roth EM, Woods DD, et al. Handoff strategies in settings with high consequences for failure: lessons for health care operations. Int J Qual Health Care. 2004;16:125-132.

Barenfanger J, Sautter RL, Lang DL, et al. Improving patient safety by repeating (read-back) telephone reports of critical information. Am J Clin Pathol. 2004;121:801-803.

Apker J, Mallak LA, Applegate EB, et al. Exploring emergency physician-hospitalist handoff interactions: development of the Handoff Communication Assessment. Ann Emerg Med. 2010;55:161-170.

Spooner AJ, Chaboyer W, Corley A, et al. Understanding current intensive care unit nursing handover practices. Int J Nurs Pract. 2013;19:214-220.

Nagpal K, Abboudi M, Manchanda C, et al. Improving postoperative handover: a prospective observational study. Am J Surg. 2013;206: 494-501.

\section{TABLES}

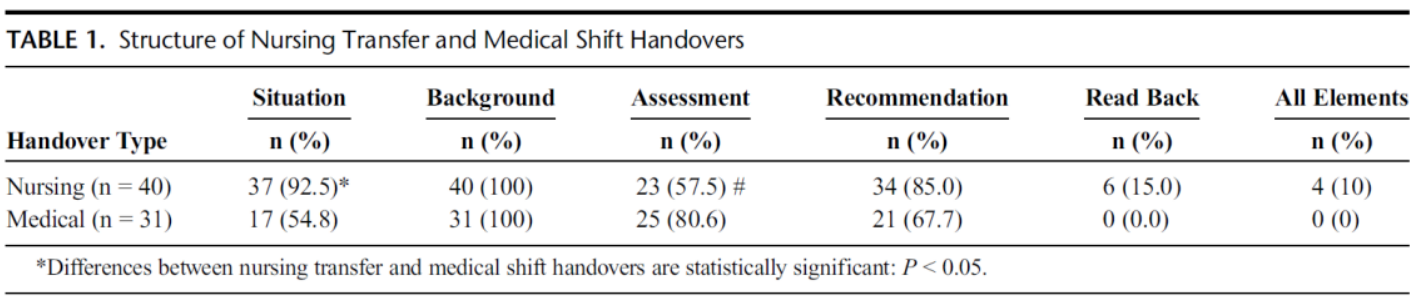

TABLE 2. Respondent Characteristics $(n=109)$

\begin{tabular}{lc}
\hline Respondents' Characteristic & $\mathbf{n}(\mathbf{\%})$ \\
\hline Sex & \\
$\quad$ Male & $30(27.5)$ \\
Female & $79(72.5)$ \\
Profession & \\
$\quad$ Nurse & $67(61.5)$ \\
Resident & $19(17.4)$ \\
Specialist & $20(18.3)$ \\
Not mentioned & $3(2.8)$ \\
Years of experience & \\
$<1$ & $19(17.4)$ \\
$1-4$ & $24(22.0)$ \\
$5-9$ & $21(19.3)$ \\
$\geq 10$ & $44(40.4)$ \\
Not mentioned & $1(0.9)$ \\
\hline
\end{tabular}


Wulp, I. van der, Poot, E.P., Nanayakkara, P.W.B., Loer, S.A., Wagner, C. Handover structure apeh quality in the acute medical assessment unit: a prospective observational study. Journal of

TABLE 3. Original and Current Factor Loadings of Rating Tool For Handover Quality

\begin{tabular}{|c|c|c|c|c|}
\hline Factor & Item & $\begin{array}{l}\text { Item } \\
\text { Number }\end{array}$ & $\begin{array}{l}\text { Original } \\
\text { Factor } \\
\text { Loading* }\end{array}$ & $\begin{array}{l}\text { Current } \\
\text { Factor } \\
\text { Loading }\end{array}$ \\
\hline IT & $\begin{array}{l}\text { All relevant information was } \\
\text { selected and communicated. }\end{array}$ & 5 & 0.71 & 0.81 \\
\hline IT & $\begin{array}{l}\text { The person handing off the } \\
\text { patient continuously used } \\
\text { the available documentation } \\
\text { to structure the handoff. }\end{array}$ & 2 & 0.69 & 0.24 \\
\hline IT & $\begin{array}{l}\text { The person handing off the } \\
\text { patient clearly communicated } \\
\text { his/her assessment of the } \\
\text { patient. }\end{array}$ & 7 & 0.64 & 0.85 \\
\hline IT & $\begin{array}{l}\text { Handoff followed a logical } \\
\text { structure. }\end{array}$ & 1 & 0.62 & 0.63 \\
\hline IT & $\begin{array}{l}\text { Not enough time was } \\
\text { allowed for the handoff. }\end{array}$ & 3 & 0.60 & 0.38 \\
\hline IT & $\begin{array}{l}\text { Priorities for further treatment } \\
\text { were addressed. }\end{array}$ & 6 & 0.58 & 0.90 \\
\hline IT & Documentation was complete. & 13 & 0.41 & 0.48 \\
\hline SA & $\begin{array}{l}\text { The team jointly ensured that } \\
\text { the handoff was complete. }\end{array}$ & 12 & 0.84 & 0.62 \\
\hline SA & $\begin{array}{l}\text { Questions and ambiguities } \\
\text { were resolved. }\end{array}$ & 11 & 0.70 & 0.67 \\
\hline SA & $\begin{array}{l}\text { Possible risks and complications } \\
\text { were discussed. }\end{array}$ & 8 & 0.67 & 0.80 \\
\hline WA & $\begin{array}{l}\text { There were tensions within } \\
\text { the team during handoff. }\end{array}$ & 10 & 0.76 & 0.57 \\
\hline WA & $\begin{array}{l}\text { It was easy to establish good } \\
\text { contact at the beginning of } \\
\text { the handoff. }\end{array}$ & 9 & 0.72 & 0.56 \\
\hline WA & $\begin{array}{l}\text { Patients' experience was } \\
\text { considered carefully } \\
\text { during handoff. }\end{array}$ & 16 & 0.52 & 0.55 \\
\hline
\end{tabular}


Wulp, I. van der, Poot, E.P., Nanayakkara, P.W.B., Loer, S.A., Wagner, C. Handover structure apeh quality in the acute medical assessment unit: a prospective observational study. Journal of

TABLE 4. Perceived Quality of Handovers $(n=85)$

\begin{tabular}{|c|c|}
\hline Rating Tool for Handover Quality Item & Frequency $(\%)$ \\
\hline \multicolumn{2}{|l|}{ Handoff followed a logical structure } \\
\hline (Partially) agree & $49(57.6)$ \\
\hline Partially) disagree & $36(42.4)$ \\
\hline \multicolumn{2}{|c|}{$\begin{array}{l}\text { The person handing off the patient continuousy } \\
\text { used the avaibble documentation to structure } \\
\text { the handoff. }\end{array}$} \\
\hline (Partially) agree & $45(52.9)$ \\
\hline (Partially) disagree & $24(28.2)$ \\
\hline Missing & $16(18.8)$ \\
\hline \multicolumn{2}{|l|}{ Not enough time was allowed for the handoff. } \\
\hline (Partially) disagree & $39(45.9)$ \\
\hline \multicolumn{2}{|c|}{$\begin{array}{l}\text { In case of interruptions during handoff, attempts } \\
\text { were made to minimize them. }\end{array}$} \\
\hline (Partially) agree & $44(51.7)$ \\
\hline (Partially) disagree & $23(27.0)$ \\
\hline Missing & $18(21.2)$ \\
\hline \multicolumn{2}{|l|}{$\begin{array}{l}\text { All relevant information was selected } \\
\text { and communicated. }\end{array}$} \\
\hline (Partially) agree & $32(37.6)$ \\
\hline (Partially) disagree & $51(60.0)$ \\
\hline Missing & $2(2.4)$ \\
\hline \multicolumn{2}{|l|}{ Priorities for further treatment were addressed. } \\
\hline (Partially) disagree & $23(27.0)$ \\
\hline Missing & $2(2.4)$ \\
\hline \multicolumn{2}{|l|}{$\begin{array}{l}\text { The person handing off the paticnt clearly } \\
\text { communicated her/his assessment of } \\
\text { the paticnt. }\end{array}$} \\
\hline (Partially) agree & $62(73.0)$ \\
\hline (Partially) disagree & $21(24.7)$ \\
\hline Missing & $2(2.4)$ \\
\hline \multicolumn{2}{|c|}{ Possible risks and complications were discussed. } \\
\hline (Partially) agrec & $57(67.1)$ \\
\hline (Partially) disagree & $26(30.6)$ \\
\hline Missing & $2(2.4)$ \\
\hline \multicolumn{2}{|l|}{$\begin{array}{l}\text { It was casy to establish good contact at the } \\
\text { beginning to the handoff. }\end{array}$} \\
\hline (Partially) agree & $55(64.7)$ \\
\hline (Partially) disagree & $11(12.9)$ \\
\hline Missing & $19(22.4)$ \\
\hline \multicolumn{2}{|c|}{ There was tension within the team during handoff. } \\
\hline (Partially) agrec & $19(22,4)$ \\
\hline (Partially) disagree & $47(55.2)$ \\
\hline Missing & $19(22,4)$ \\
\hline \multicolumn{2}{|l|}{ Questions and ambiguities were resolved. } \\
\hline (Partially) agree & $65(76.5)$ \\
\hline (Partially) disagree & $17(20.0)$ \\
\hline Misssing & $3(3.5)$ \\
\hline \multicolumn{2}{|l|}{$\begin{array}{l}\text { The team jointly ensured that the handoff } \\
\text { was complete. }\end{array}$} \\
\hline (Partially) agree & $72(84.7)$ \\
\hline (Partially) disagree & $10(11.8)$ \\
\hline Missing & $3(3.5)$ \\
\hline $\begin{array}{l}\text { Documentation was complete. } \\
\text { (Partially) agree }\end{array}$ & $54(63.6)$ \\
\hline
\end{tabular}

TABLE 4. (Continued)

(Partially) disagree

Missing

$28(32.9)$

There was toor

$3(3.5)$

(Partially) agree

(Partially) disagree

Missing

$8(9.4)$

$74(87.1)$

$3(3.5)$

Too much information was askod for

(Partially) agrec

(Partially) disagree

$8(9.4)$

$74(87.0)$

$3(3.5)$

The patient's experience was considered carefully during handoff.

(Partially) agree

(Partially) disagree

Missing

$29(34.2)$

Overall, the quality of this handoff was high.

(Partially) agrec

$46(54.2)$

(Partially) disagree

Missing

$36(42.3)$

$3(3.5)$

The person handing off the patient was under time pressure.

(Partially) agrec

(Partially) disagree

Missing

$3(3.5)$

The person taking on responsibility for the patient was under time pressure.

(Partially) agree

(Partially) disagree

Missing 